\title{
Strain localisation behaviour of cemented paste backfill
}

\author{
Y Zhao BGRIMM Technology Group, China \\ LJ Guo BGRIMM Technology Group, China
}

A Taheri The University of Adelaide, Australia

M Karakus The University of Adelaide, Australia

A Deng The University of Adelaide, Australia

\begin{abstract}
Mine tailings are the most significant and most problematic sources of solid waste globally in the mining industry. The developing concept of sustainable mining warrants reusing mine wastes, particularly tailings. Cemented paste backfill (CPB) is a backfill method composed of dewatered tailings, a cementitious binder, and processed mine water. CPB reuses tailings in underground mine excavations, and as such, reduces the amount of surface-disposed tailings, mitigates the potential environmental impacts, and assists waste management. In this study, the strain localisation behaviour of a South Australian copper-gold underground mine CPB system was evaluated through a comprehensive experimental programme. Understanding the strain localisation behaviour helps evaluate CPB damage evolution and failure mechanism under real-life loading regimes. The three-dimensional digital image correlation (DIC) technique was used to measure the full-field of strain development on the surface of CPB samples during unconfined compressive strength (UCS) tests. With the use of several virtual extensometers, the axial and lateral strains of CPB samples, with and without strain localisation, in both pre-peak and post-peak regimes are characterised. Overall, the DIC technique provides more accurate stress-strain relations of CPB samples than conventional external measurement devices. The DIC test results indicate that strain localisation of CPB samples initiates in the pre-peak regime at around $80 \%$ of the UCS. The greater the binder content and the longer the curing time, the higher the axial stress level required to initiate localisation to the UCS, thus emulating the failure mechanism of quasi-brittle materials - rock and concrete. Finally, with the increase of curing time, the difference between strain values at the localised and non-localised zones became less significant in the pre-peak regime and more pronounced in the post-peak regime.
\end{abstract}

Keywords: tailings, cemented paste backfill, digital image correlation, strain localisation

\section{Introduction}

Mine tailings are the most significant and most problematic sources of solid waste globally in the mining industry. The developing concept of sustainable mining warrants reusing mine wastes, particularly tailings (Qian et al. 2011; Jones \& Boger 2012; Naganathan et al. 2012; Zhang et al. 2019). Cemented paste backfill $(C P B)$ is a backfill method mixing dewatered tailings, a cementitious binder and processed mine water to form a non-settling slurry for simple pumping into mined cavities resulted from underground mine operations (Fall et al. 2010; Liu et al. 2017; Li \& Fall 2018; Zhang et al. 2018; Zhao et al. 2018). To obtain the non-settling characteristic with appropriate rheological behaviour, the solids content of CPB often falls in the range of 70-85\% solids by weight (Rankine \& Sivakugan 2007; Orejarena \& Fall 2010; Sivakugan et al. 2015.). The use of $C P B$ in underground mine excavations recycles tailings required for surface disposal, mitigates the burden on the environment, reduces tailings disposal costs, and assists waste management (Li \& Fall 2018; Zhao et al. 2019; Zhao et al. 2020).

Strain localisation is a phenomenon that describes the non-uniform deformation under various loading conditions (Weidner \& Biermann 2021). During the failure process under uniaxial compressive loading, 
according to the compressive damage zone (CDZ) framework, the strain localisation occurs at the local damage zone (LDZ) where a single major crack (i.e. single shear failure) or multiple major cracks (i.e. splitting failure) were distributed (Tung \& Tue 2015; Munoz et al. 2016). In this framework, the overall strain (deformation) measured by traditional methods only describes the compressive behaviour of the entire sample. The large deformations accumulated near the LDZ, strain localisation, could be measured by the three-dimensional digital image correlation (DIC) technique (Panteleev et al. 2014; Munoz \& Taheri 2017, 2019).

The three-dimensional DIC technique is a non-contact method that acquires images of an object in digital form, and performs image analysis to extract full-field shape, deformation and motion measurements, which allows both general strain distributions and localised strain concentrations to be observed (Oka et al. 2018; Mao et al. 2019; Munoz \& Kiyota 2020). The DIC technique was initially invented in the early 1980s (Dai et al. 2019). Since its advent, DIC applications have been rapidly growing in many conventional structural testing applications in composite structures to measure the full-field of strain development on the surface of samples, and characterise the deformations and strains of samples with and without strain localisation (Shadmehri \& Hoa 2019; Weidner \& Biermann 2021). For CPBs, traditional strain measurement methods such as linear variable differential transducer (LVDT), chain extensometers, and strain gauges, which only measure displacements or strains at specific, isolated points, have critical disadvantages in the installation process and recording capabilities (Gencturk et al. 2014; del Rey Castillo et al. 2019). The accurate deformation (strain) measurement and the understanding of strain localisation behaviour are critical to evaluating CPB systems' damage evolution and failure mechanism. However, a literature survey indicates limited research has been reported on the accurate strain measurement and the understanding of strain localisation behaviour of CPB systems (Sun et al. 2019; Zhao et al. 2019).

In this present study, a series of unconfined compressive strength (UCS) tests were carried out on various ordinary Portland cement (PC) mix designs to evaluate the influence of binder contents and curing time on the localisation behaviour of the CPB system. During the UCS test, the three-dimensional DIC technique was used to measure the full-field deformation and characterise the relationships between strain localisation and the macro-scale mechanical deformations of the CPB sample. Finally, using several virtual extensometers, the state of strain localisation was investigated in both the axial and lateral directions.

\section{$2 \quad$ Methodology}

\subsection{Materials}

The tailings are from a copper-gold underground mine located in South Australia and used in the present study. The physical properties, including specific gravity, grain size data, and Atterberg limits, are given in Table 1 as per relevant American Society for Testing and Materials and Australian standards. The chemical composition of the tailings is also provided in Table 1 . The chemical composition mainly consists of silicon dioxide $\left(\mathrm{SiO}_{2}\right)$ and iron oxide $\left(\mathrm{Fe}_{2} \mathrm{O}_{3}\right)$, with mass fractions of 38.27 and $37.70 \%$, respectively.

Ordinary PC was used as the binder in this study and was mixed with processed water, which was sourced from the South Australian copper-gold underground mine. The $\mathrm{pH}$ of processed water was found to be 7.5, from which the water was characterised as a neutral substance. The chemical composition of processed mine water is presented in Table 2. 
Table 1 Physical and chemical composition of the used tailings

\begin{tabular}{llll}
\hline Physical properties & Value & Chemical component & Mass percentage (\%) \\
\hline Specific gravity, $\mathrm{G}_{\mathrm{s}}$ & 2.61 & $\mathrm{SiO}_{2}$ & 38.27 \\
Fines $(<75 \mu \mathrm{m})(\%)$ & 38.6 & $\mathrm{Fe}_{2} \mathrm{O}_{3}$ & 37.70 \\
Fine sand $(0.075-0.425 \mathrm{~mm})(\%)$ & 55.2 & $\mathrm{Al}_{2} \mathrm{O}_{3}$ & 7.19 \\
Medium sand $(0.425-2 \mathrm{~mm})(\%)$ & 6.2 & $\mathrm{~K}_{2} \mathrm{O}$ & 2.33 \\
Liquid limit, $w_{\mathrm{L}}(\%)$ & 19.2 & $\mathrm{Ca}$ & 0.81 \\
Plastic limit, $w_{\mathrm{P}}(\%)$ & 13.1 & $\mathrm{Mg}$ & 0.75 \\
Plasticity index, $\mathrm{IP}(\%)$ & 6.1 & $\mathrm{Ti}$ & 0.56 \\
Optimum water content, $w_{\text {opt }}(\%)$ & 8.7 & $\mathrm{Na}_{2} \mathrm{O}$ & 0.07 \\
Maximum dry unit weight, $\gamma_{\text {dmax }}\left(\mathrm{kN} / \mathrm{m}^{3}\right)$ & 20.2 & $\mathrm{Other}$ & 12.32 \\
\hline
\end{tabular}

Table 2 Chemical composition of processed water

\begin{tabular}{ll}
\hline Processed water component & Value $(\mathrm{mg} / \mathrm{L})$ \\
\hline $\mathrm{CL}^{-}$ & 5,800 \\
$\mathrm{SO}_{4}{ }^{2-}$ & 2,400 \\
$\mathrm{NO}^{3-}$ & 6 \\
$\mathrm{Na}^{+}$ & 3,800 \\
$\mathrm{Ca}^{2+}$ & 480 \\
$\mathrm{~K}^{+}$ & 380 \\
$\mathrm{Mg}^{2+}$ & 280 \\
\hline
\end{tabular}

\subsection{Sample preparation}

In this study, a series of the sample with different binder content was prepared. A total of seven mixing designs, as outlined in Table 3, were prepared. For ease of presentation, the following coding system is used to designate the various mix designs:

$$
P_{a} T_{\mathrm{b}}
$$

where:

$$
\begin{aligned}
& \mathrm{P}_{\mathrm{a}}=\mathrm{a} \% \mathrm{PC} \text { content. } \\
& \mathrm{T}_{\mathrm{b}}=\mathrm{b} \text { days of curing. }
\end{aligned}
$$

The tailings and PC were blended in dry form for approximately five minutes to gain visible homogeneity of the ingredients according to the selected mix designs outlined in Table 3 . Then required amounts of processed water corresponding to a solids content of SC $=77 \%$ was added to each blend and thoroughly mixed by a mechanical mixer to obtain a uniform consistency. The resultant slurries were poured into cylindrical moulds, measuring $100 \mathrm{~mm}$ in height and $42 \mathrm{~mm}$ in diameter, in one-third length increments; each layer was tamped 25 times using a small metal rod to remove entrapped air. The moulds were then transferred to a humidity chamber, maintained at $70 \%$ relative humidity and a temperature of $25^{\circ} \mathrm{C}$, where curing was allowed for 14 days before de-moulding. For those mix designs containing 4\% PC, additional curing periods of 28 and 56 days were also considered. After de-moulding, the two ends of the samples were covered with a thin layer of dental paste to ensure a flat surface for uniform load distribution during compressive loading. 
Table 3 Mix designs and their properties

\begin{tabular}{llll}
\hline Designation & PC (\%) & SC (\%) & Curing time (days) \\
\hline P1T14 & 1 & 77 & 14 \\
P2T14 & 2 & 77 & 14 \\
P3T14 & 3 & 77 & 14 \\
P4T14, 28, 56 & 4 & 77 & $14,28,56$ \\
P5T14 & 5 & 77 & 14 \\
\hline
\end{tabular}

\subsection{Unconfined compressive strength test with three-dimensional digital image correlation technique}

The prepared samples were subjected to the UCS test using a closed-loop servo-controlled testing machine (Instron-1342) with a loading capacity of $250 \mathrm{kN}$. The loading rate of the UCS test was set to $0.1 \mathrm{~mm} / \mathrm{min}$. The device has two external LVDTs to measure axial displacements. A direct-contact lateral extensometer (MTS Systems Corp. series-632.12F20) was used to measure the lateral deformation of CPB samples during compression. Moreover, a three-dimensional DIC (Fujinon-HF75SA-1) system was used to monitor the full-field deformation and strain localisation behaviour of CPB samples.

Holistically, the three-dimensional DIC system is using two high-resolution digital cameras positioned at two different angles. Using the digital images captured from two different directions during compressive loading, the three-dimensional shape of the sample can be created. From the image acquired during undeformed and subsequent deformed states, the deformation of the sample can hence be calculated (Song et al. 2013). Prior to testing, the CPB sample was painted with a black and white speckle pattern. This is completed to establish a reference to correlate spraying the undeformed image, and the images during deformed states (Sun et al. 2019; Weidner \& Biermann 2021). Figures $1 a$ and b illustrates the two high-resolution digital cameras (Fujinon HF75SA-1), which have been placed symmetrically focused on the centre of the testing sample to capture digital greyscale images during the UCS test. Two adjustable gooseneck halogen lights were used to provide uniform illumination on the sample's surface during imaging. Before the UCS tests, to recognise the shape of each test sample, the system was calibrated using a $30 \mathrm{~mm}$ target plastic plate with a uniformly spaced marker grid and taking approximately 30 images together with the testing sample (Munoz et al. 2016). Once calibration has been completed, the two cameras capture images automatically using the VIC-Snap (Correlated Solutions Inc.) software package during the UCS test, at a frame rate of one picture per second. The VIC-3D software (Correlated Solutions Inc.) then uses the first set of the images captured as an undeformed reference state to process the full-field deformation of the tested sample.

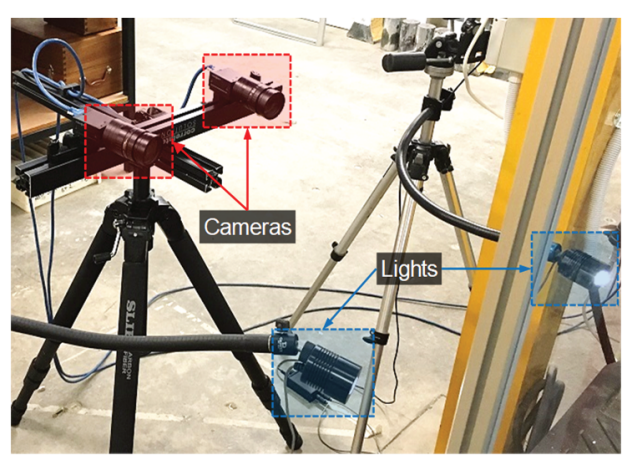

(a)

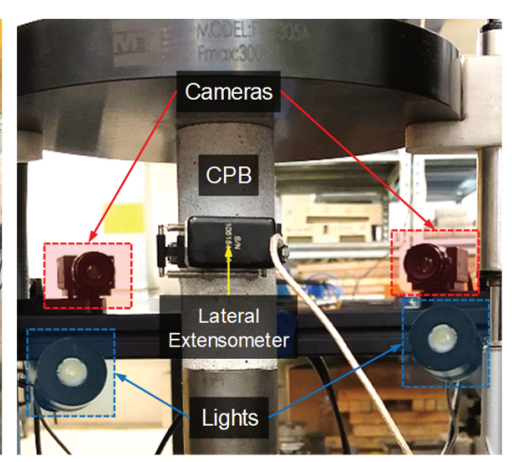

(b)

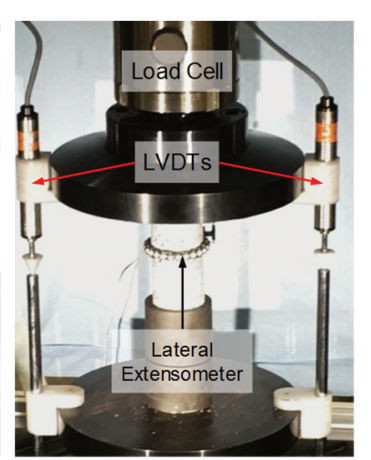

(c)

Figure 1 Three-dimensional DIC system setup. (a) Camera and light setup; (b) Rear view of the overall setup; (c) Front view of the general setup (Zhao et al. 2019) 


\section{$3 \quad$ Results and discussions}

\subsection{Field strain patterns}

Figures 2a and $\mathrm{b}$ illustrate the full-field strain development for sample P4T14 at various axial stress levels. As shown in Figure 2, eight stress levels in both pre-peak and post-peak regimes were selected, which are $0.25 q_{u}$, $0.5 q_{u}, 0.75 q_{u}$ and $q_{u}$ (peak stress) in the pre-peak regime and $0.9 q_{u}, 0.7 q_{u}, 0.5 q_{u}$ and $0.3 q_{u}$ in the post-peak regime. According to the CDZ framework, for quasi-brittle materials, like rock or concrete, the failure process under uniaxial compressive loading takes place at a single major crack (single shear failure) or multiple major cracks (splitting failure) (van Mier 2008; Tung \& Tue 2015).

Upon achieving the peak stress, accumulated deformation takes place outside the cracks and is referred to as strain localisation (Panteleev et al. 2014; Munoz \& Taheri 2017, 2019; Sun et al. 2019). For sample P4T14, the full-field strain development exhibited a uniform colour pattern until $0.75 q_{u}$, thus the sample undergoes a uniform compression during loading before $0.75 q_{\mathrm{u}}$. At peak stress, the light purple colour indicates a potential share failure line, hence a linear plane of LDZ takes place.

In the post-peak regime, as shown in Figure $2 \mathrm{~b}$, the colour gradient exhibited a non-uniform, blue to purple colour pattern, and various vertical and horizontal shear bands were found at different locations. The CPB samples tested in this study which contain low PC show the strain evolution may be different from rock and concrete; normal shear faulting was not observed. The full-field development of lateral strain for sample P4T14 is similar to the axial strain development, and these similarities were consistently observed for all of the tested samples; hence the colour patterns for full-field lateral strain development of CPB samples are not presented.

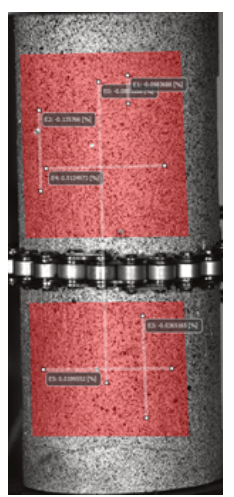

$0.25 q_{\mathrm{u}}$

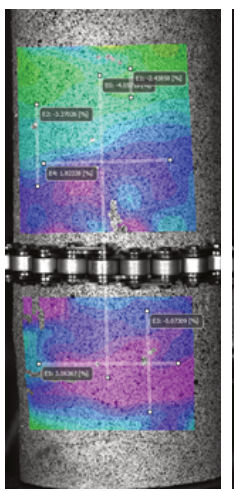

$0.90 q_{\mathrm{u}}$

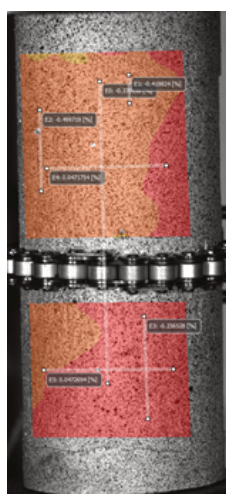

$0.50 q_{\mathrm{u}}$

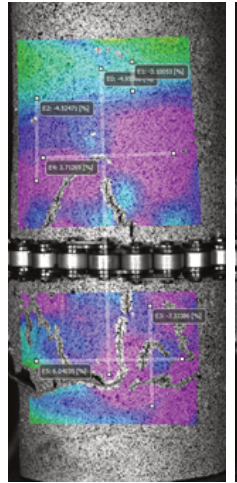

$0.70 q_{\mathrm{u}}$

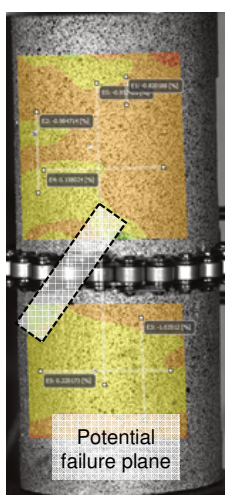

$0.75 q_{\mathrm{u}}$

(a)

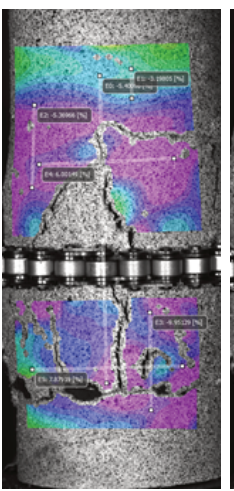

$0.50 q_{\mathrm{u}}$

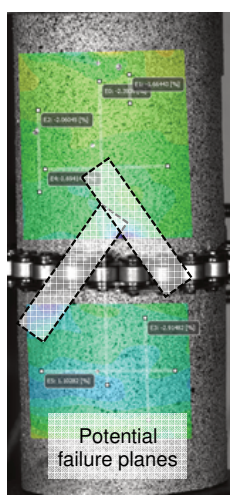

$\operatorname{Peak}\left(q_{\mathrm{u}}\right)$

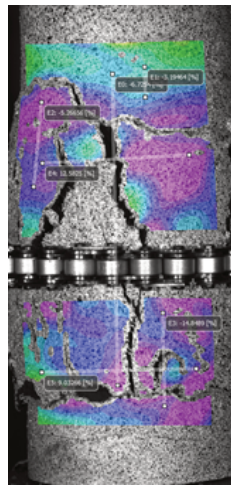

$0.30 q_{\mathrm{u}}$

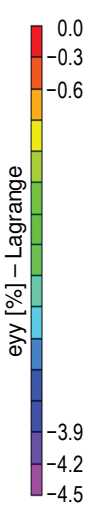

-4.2
-4.5

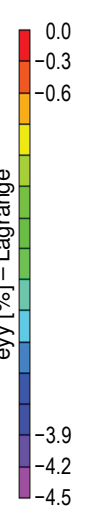

(b)

Figure 2 Full-field strain development at various axial stress levels for the sample P4T14: (a) Axial pre-peak; (b) Axial post-peak (Zhao et al. 2019) 


\subsection{Factors affecting strain localisation}

The binder content and curing time were found to influence the strain development for CPB samples. Figure 3 illustrates the effect of PC content on the full-field axial strain development at various stress levels. Similar to sample P4T14, for samples P1T14, P2T14, P3T14 and P5T14, the strain localisation behaviour was found before or immediately after the peak strength with multiple vertical and horizontal shear bands in various locations during the failure process. None of the samples exhibited typical shear failures like rock or concrete. However, with the increase of PC content, the strength of CPB increased, and the failure pattern gradually transitions from 'multiple irregular extension'-where multiple vertical and horizontal fractures occurred along with the tested sample (e.g. P1T14 in Figure 3a) - to 'multiple fracturing' - where the sample failed in the form of several planes or shear faulting (e.g. P5T14 in Figure 3d).

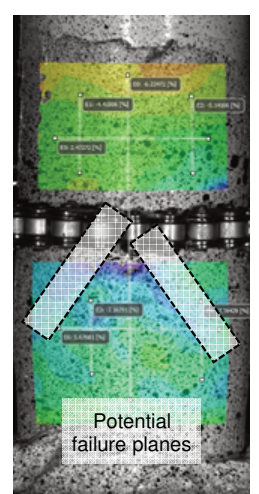

$\operatorname{Peak}\left(q_{\mathrm{u}}\right)$

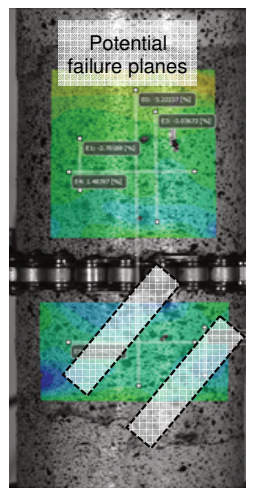

$\operatorname{Peak}\left(q_{\mathrm{u}}\right)$

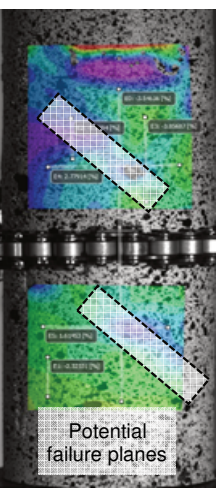

$\operatorname{Peak}\left(q_{\mathrm{u}}\right)$

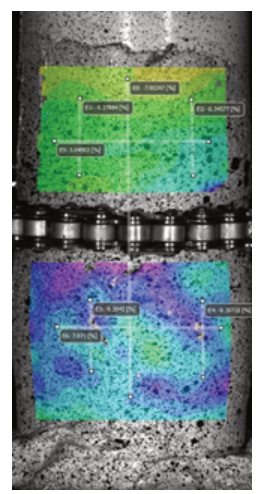

$0.90 q_{\mathrm{u}}$

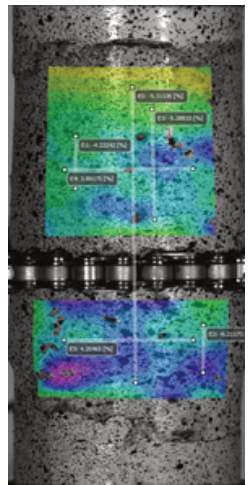

$0.90 q_{\mathrm{u}}$

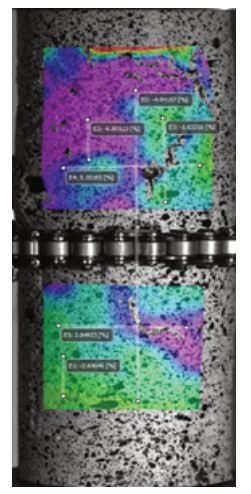

$0.90 q_{\mathrm{u}}$

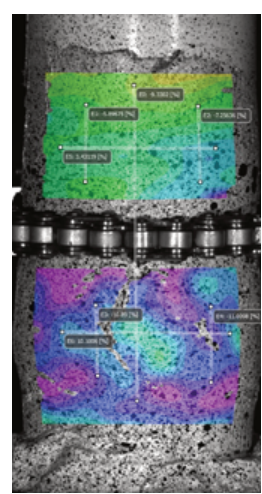

$0.70 q_{\mathrm{u}}$

(a)

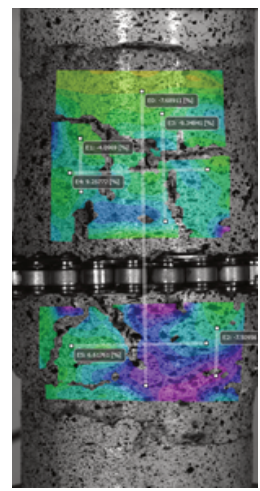

$0.70 q_{\mathrm{u}}$

(b)

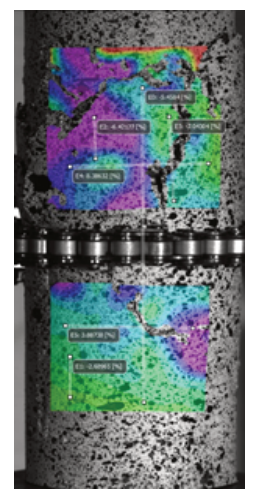

$0.70 q_{\mathrm{u}}$

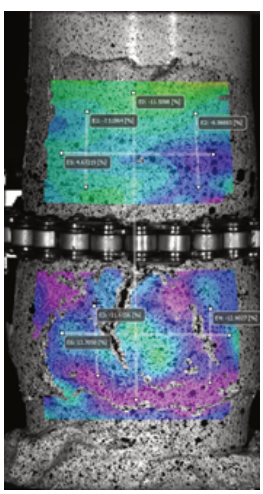

$0.50 q_{\mathrm{u}}$

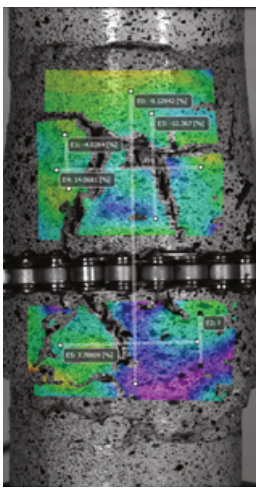

$0.50 q_{\mathrm{u}}$

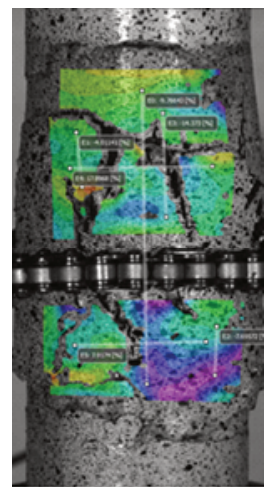

$0.30 q_{\mathrm{u}}$

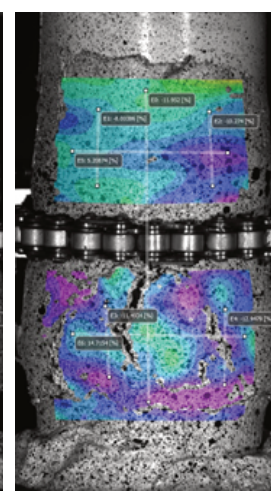

$0.30 q_{\mathrm{u}}$

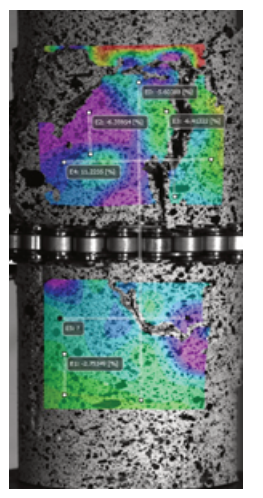

$0.50 q_{\mathrm{u}}$

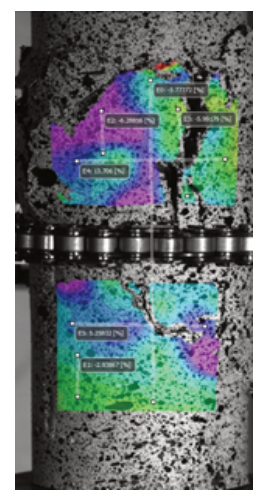

$0.30 q_{\mathrm{u}}$

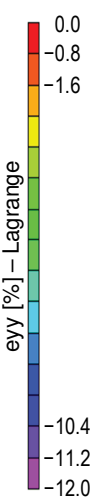

$-12.0$

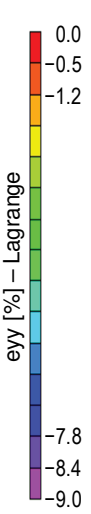

-7.8
-8.4
-9.0

(c) 


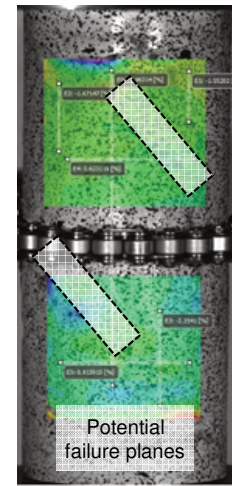

Peak $\left(q_{\mathrm{u}}\right)$

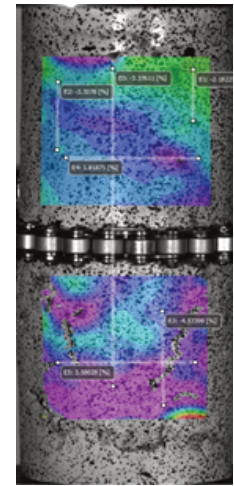

$0.90 q_{\mathrm{u}}$

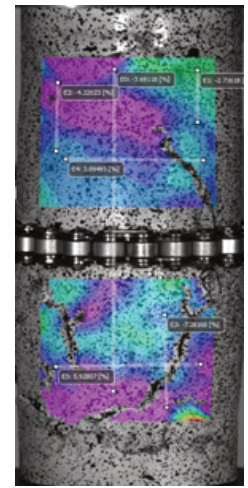

$0.70 q_{\mathrm{u}}$

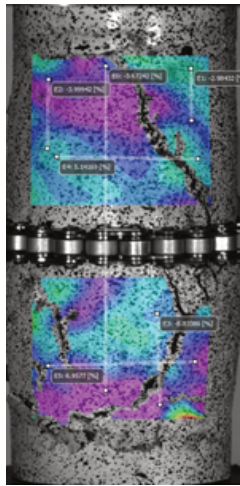

$0.50 q_{\mathrm{u}}$

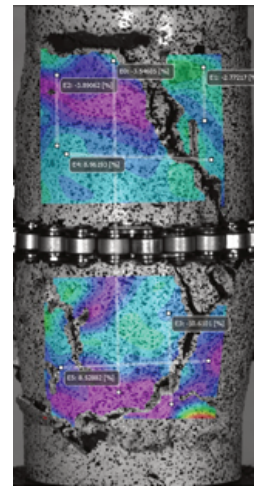

$0.30 q_{\mathrm{u}}$

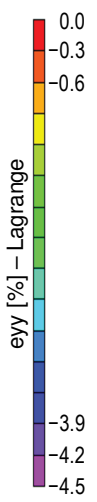

(d)

Figure 3 Effect of PC content on strain localisation. Full-field axial strain development at various post-peak stress levels: (a) P1T14; (b) P2T14; (c) P3T14; (d) P5T14 (Zhao et al. 2019)

Figure 4 illustrates the effects of curing time on the strain localisation behaviour of CPB. In Figure 4, the full-field axial strain development at various stress levels of samples P4T14, P4T28 and P4T56 in the post-peak regime were displayed.

In Figures $4 \mathrm{a}$ and b, samples P4T14 and P4T28 had some irregular strain localisation on the surface, where visual comparison shows the area of LDZ reduced in size due to the increase in curing time. For sample P4T28, the image showed some blue colour at peak stress, which may be defined as a potential failure zone. However, the failure pattern of P4T28 was two large X-shaped shear bands with some irregular micro-cracks that occurred on the surface.

For sample P4T56, Figure 4c showed a thin blue colour layer signifying the potential failure plane right after the peak. Unlike the samples with less curing time, the failure pattern of sample P4T56 became a single visible shear near the potential failure plane, accompanied by some minor cracks. With the increase of curing time, the failure pattern of $\mathrm{CPB}$ samples was found to transition towards more pronounced shear faulting behaviour as it provides sufficient time for binder hydration, which became similar to the failure pattern of rock-like materials (Nguyen et al. 2011). Hence, the greater the PC content, and more importantly, the longer the curing period, the more consistent the stress-strain evolution with conventional quasi-brittle materials such as rock and concrete.

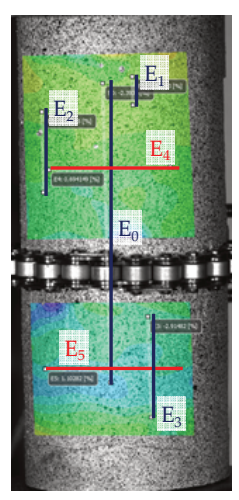

$\operatorname{Peak}\left(q_{\mathrm{u}}\right)$

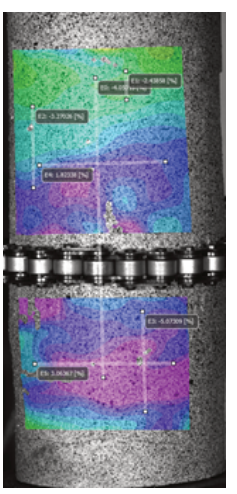

$0.90 q_{\mathrm{u}}$

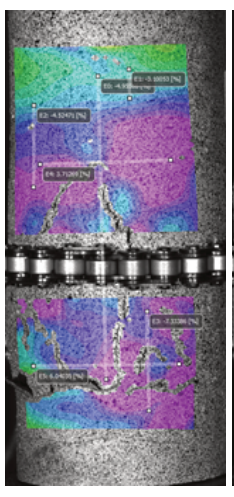

$0.70 q_{\mathrm{u}}$

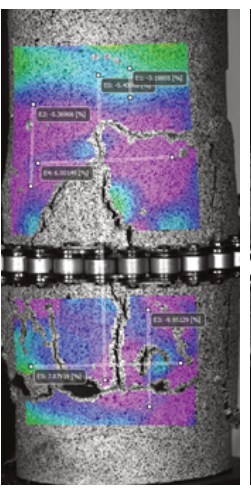

$0.50 q_{\mathrm{u}}$

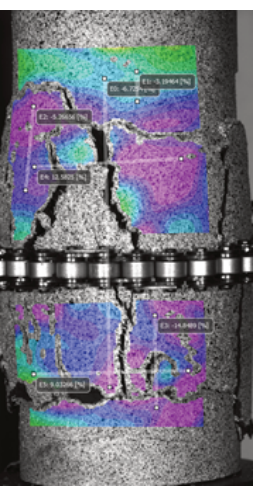

$0.30 q_{\mathrm{u}}$

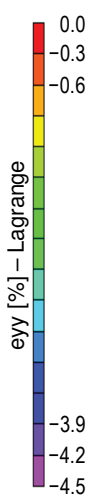

(a) 


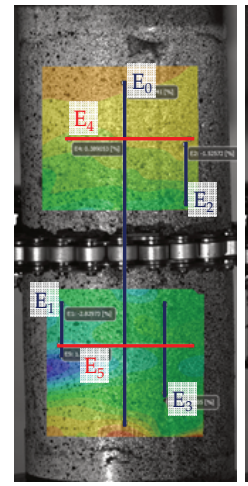

Peak $\left(q_{\mathrm{u}}\right)$

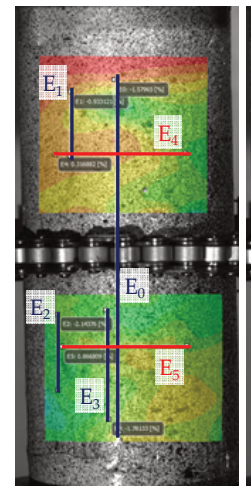

$\operatorname{Peak}\left(q_{\mathrm{u}}\right)$

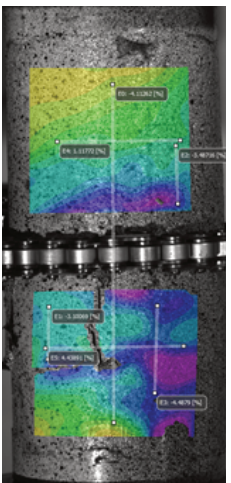

$0.90 q_{\mathrm{u}}$

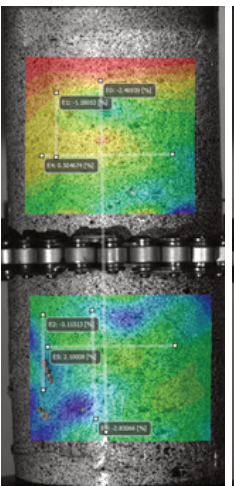

$0.90 q_{\mathrm{u}}$

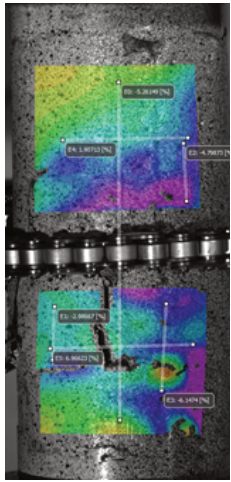

$0.70 q_{\mathrm{u}}$

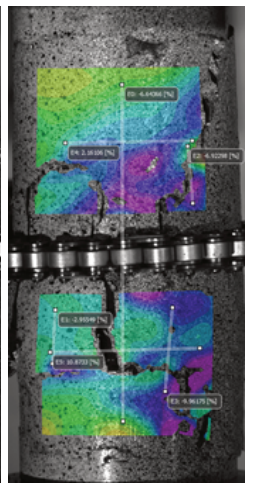

$0.50 q_{\mathrm{u}}$

(b)

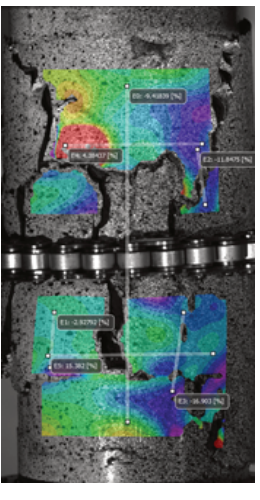

$0.30 q_{\mathrm{u}}$

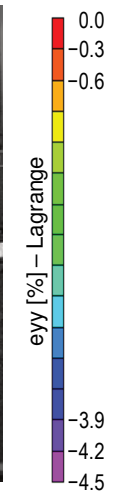

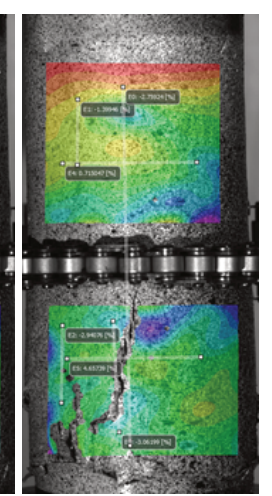

$0.50 q_{\mathrm{u}}$

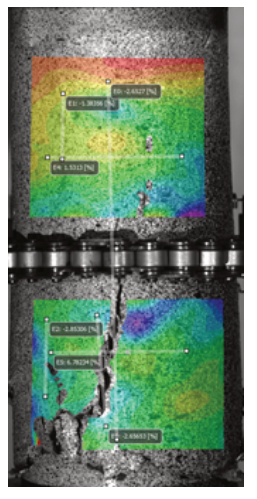

$0.30 q_{\mathrm{u}}$

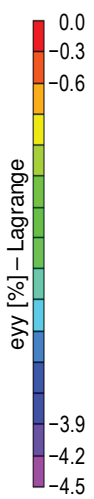

$0.70 q_{\mathrm{u}}$

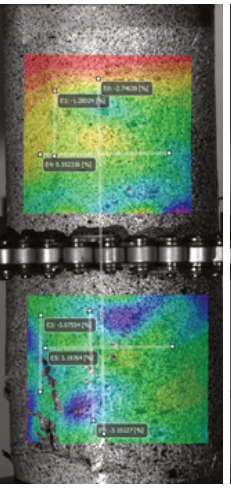

(c)

Figure 4 Effect of curing time on strain localisation. Full-field axial strain development at various post-peak stress levels: (a) P4T14; (b) P4T28; (c) P4T56 (Zhao et al. 2019)

\subsection{Validation and localisation behaviour of the stress-strain curves}

The three-dimensional DIC technique is a non-contact method that can measure the full-field of strain development on the surface of samples, and characterise the deformations and strains of samples in various positions and directions (Shadmehri \& Hoa 2019; Weidner \& Biermann 2021). With the use of VIC-3D software, the DIC system can measure the deformation between any two points on the surface of a sample by simply adding a virtual extensometer. In this study, two traditional strain measurement methods were applied; the LVDT for axial strain and the direct-contact lateral extensometer for lateral strain. As shown in Figure 4, four axial virtual extensometers were used in each CPB sample, E0 measures the overall axial deformation (compared to LVDT); E1 measures the strain outside the LDZ; E2 and E3 measures the axial deformation around or inside of the LDZ, and hence captures the strain localisation behaviour. Similarly, two lateral virtual extensometers, E4 and E5 (in Figure 4), measure the lateral strains outside and inside of the LDZ. Figure 5 illustrates the stress-strain curves for samples P4T14, P4T28 and P4T56 obtained using various measurement techniques. For the overall axial strains measured by LVDT and E0, the trend is similar with a certain level of bedding error caused by the LVDT device. As the bedding error varies for different samples, the DIC technique free from bedding errors improves the degree of accuracy for CPB stress-strain measurement (Nguyen et al. 2011; Zhang et al. 2012; Song et al. 2013). 
As shown in Figure 5, for samples P4T14, P4T28 and P4T56, the stress-strain curves of the axial virtual extensometers (E0, E1, E2 and E3) and the lateral virtual extensometers E4 and E5 overlap with each other in most of the pre-peak regime (up to $80 \%$ of peak stress). This proves the observation in Section 3.1 that CPB samples undergo uniform compression within most pre-peak regimes. After reaching peak stress, strain localisation takes place for all CPB samples, and the three axial virtual extensometers (E1, EO and E2, representing axial deformation outside the LDZ, overall axial deformation and axial deformation inside the LDZ), and two lateral virtual extensometers (E4 and E5, representing lateral deformation outside the LDZ and lateral deformation inside the LDZ) generate different values with notable differences.

As shown in Figure 5 and Table 4, the stress value where localisation initiates $\left(q_{1}\right)$ could be found when E1, E0 and E2 (or E4 and E5) stress-strain curves start to differ. The $q_{1}$ values for samples P4T14, P4T28 and P4T56 are 202.5, 259.5 and $372.8 \mathrm{kPa}$. Considering the peak stress for samples P4T14, P4T28 and P4T56 $(265.3,325.2$ and $432.7 \mathrm{kPa})$, samples P4T14, P4T28 and P4T56 start localisation at the stress level of 76, 80 and $86 \%$ peak stress, respectively. With the increase in curing time, the stress level of localisation initiation approaches the peak stress, thus the failure mechanism of CPB samples transitions towards quasi-brittle materials (Munoz \& Taheri 2017, 2019).

Table 4 Stress value where localisation initiates for sample P4T14, P4T28 and P4T56

\begin{tabular}{llll}
\hline Designation & $\mathbf{q}_{1}(\mathbf{k P a})$ & $\mathbf{q}_{\mathrm{u}}(\mathbf{k P a})$ & Localisation initiation \\
\hline P4T14 & 202.5 & 265.3 & $76.3 \% \mathrm{q}_{u}$ \\
P4T28 & 259.5 & 325.2 & $79.8 \% \mathrm{q}_{u}$ \\
P4T56 & 372.8 & 432.7 & $86.2 \% \mathrm{q}_{\mathrm{u}}$ \\
\hline
\end{tabular}

In Figure 5a and Table 5, sample P4T14 reached peak stress at 2.49, 3.11 and 3.46\% deformation for E1, E0 and E2, respectively. With the increase in curing time, samples P4T28 and P4T56 reached peak stress at 2.05, 2.45 and $2.63 \%$, and $1.31,1.46$ and $1.67 \%$ based on E1, E0 and E2, respectively. Hence, the magnitude of localisation becomes less significant in the pre-peak regime. Moreover, as shown in Figure 5 and Table 5, with the increase in time, the localisation behaviour becomes more significant in the post-peak regime as the difference between E1, E0 and E2 (or E4 and E5) stress-strain curves become increasingly notable.

Table 5 Axial and lateral deformation at peak stress detected for sample P4T14, P4T28 and P4T56 using various techniques

\begin{tabular}{lllllllll}
\hline \multirow{2}{*}{ Designation } & \multicolumn{8}{c}{ Axial and lateral deformation at $\mathbf{q}_{\mathbf{u}}$} \\
& E0 & E1 & E2 & E3 & LVDT & E4 & E5 & Extensometer \\
\hline P4T14 & $3.11 \%$ & $2.49 \%$ & $3.42 \%$ & $4.13 \%$ & $3.91 \%$ & $-1.29 \%$ & $-2.51 \%$ & $-1.43 \%$ \\
P4T28 & $2.45 \%$ & $2.05 \%$ & $2.63 \%$ & $2.84 \%$ & $3.44 \%$ & $-0.54 \%$ & $-1.85 \%$ & $-1.93 \%$ \\
P4T56 & $1.46 \%$ & $1.31 \%$ & $1.67 \%$ & $1.98 \%$ & $2.67 \%$ & $-0.24 \%$ & $-1.14 \%$ & $-1.23 \%$ \\
\hline
\end{tabular}




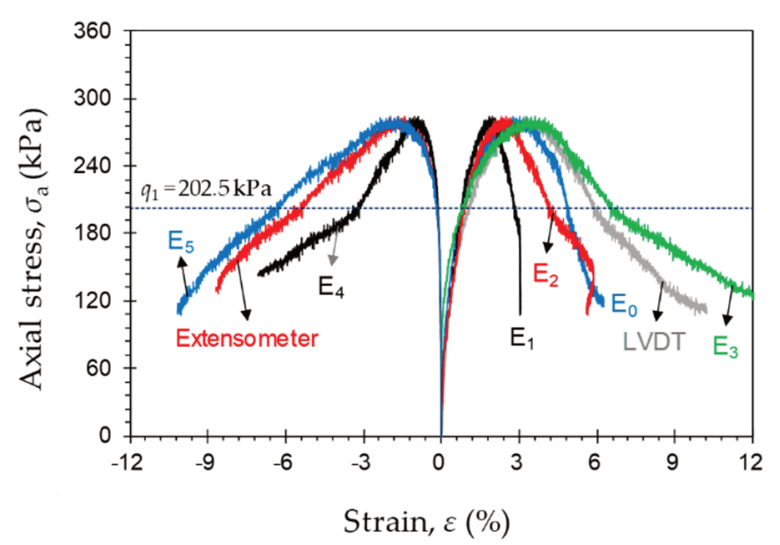

(a)

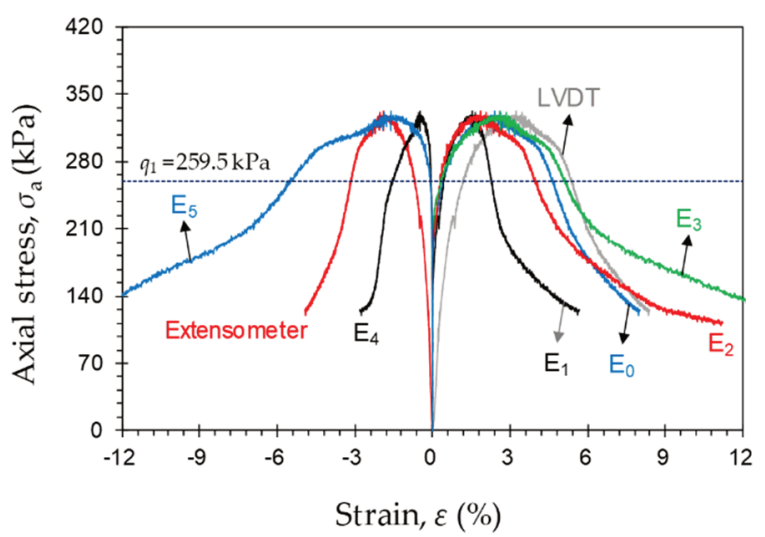

(b)

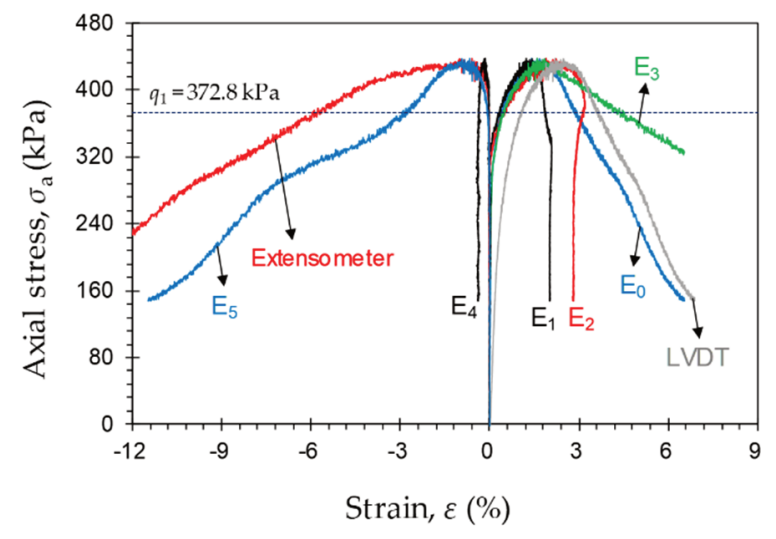

(c)

Figure 5 Comparison of DIC technique and traditional strain measurement methods. Stress-strain curves obtained using various measurement techniques, for the tested samples: (a) P4T14; (b) P4T28; (c) P4T56

\section{Conclusion}

From the research and methodology described above, the following conclusions can be determined:

- The DIC technique free from bedding errors as opposed to external measurement devices improves the degree of accuracy for CPB stress-strain measurement.

- The CPB samples undergo uniform compression within most pre-peak regimes. With the increase of binder content and curing time, the failure pattern of CPB samples transferred from multiple irregular fractures to single shear failure and became more consistent with conventional quasi-brittle materials such as rock and concrete.

The virtual extensometers used in the DIC technique show that the strain localisation of CPB samples initiates around $80 \%$ of peak stress in the pre-peak regime. The stress level for samples P4T14, P4T28 and P4T56 to start localisation are 76,80 and $86 \%$ of peak stress, respectively. With the increase in curing time, the stress level of localisation initiation approaches the peak stress. Moreover, with the increase of curing, the magnitude of localisation becomes less significant in the pre-peak regime and more evident in the post-peak regime. Finally, as there were only seven samples made in total for this study, further study should be carried out to validate the backfill strain localisation behaviour. 


\section{Acknowledgement}

Financial support from the National Key Research and Development Program of China (2018YFE0123000SQ2018YFE011020) is gratefully acknowledged and the Key Research Fund of BGRIMM (02-1911). This research was also partially funded by Mining Education Australia (MEA) and OZ Minerals, Australia; their support is gratefully acknowledged.

\section{References}

Dai, S, Liu, X \& Nawnit, K 2019, 'Experimental study on the fracture process zone characteristics in concrete utilising DIC and AE methods', Applied Sciences, vol. 9, no. 7, https://doi.org/10.3390/app9071346

del Rey Castillo, E, Allen, T, Henry, R, Griffith, M \& Ingham, J 2019, 'Digital image correlation (DIC) for measurement of strains and displacements in coarse, low volume-fraction FRP composites used in civil infrastructure', Composite Structures, vol. 212, pp. 43-57, https://doi.org/10.1016/j.compstruct.2019.01.024

Fall, M, Célestin, JC, Pokharel, M \& Touré, M 2010, 'A contribution to understanding the effects of curing temperature on the mechanical properties of mine cemented tailings backfill', Engineering Geology, vol. 114, no. 3-4, pp. 397-413, https://doi.org/10.1016/j.enggeo.2010.05.016

Gencturk, B, Hossain, K, Kapadia, A, Labib, E \& Mo, Y-L 2014, 'Use of digital image correlation technique in full-scale testing of prestressed concrete structures', Measurement, vol. 47, pp. 505-515, https://doi.org/10.1016/j.measurement.2013.09.018

Jones, H \& Boger, DV 2012, 'Sustainability and waste management in the resource industries', Industrial \& Engineering Chemistry Research, vol. 51, no. 30, pp. 10057-10065, https://doi.org/10.1021/ie202963z

Li, W \& Fall, M 2018, 'Strength and self-desiccation of slag-cemented paste backfill at early ages: link to initial sulphate concentration', Cement and Concrete Composites, vol. 89, pp. 160-168, https://doi.org/10.1016/j.cemconcomp.2017.09.019

Liu, G, Li, L, Yang, X \& Guo, L 2017, 'Numerical analysis of stress distribution in backfilled stopes considering interfaces between the backfill and rock walls', International Journal of Geomechanics, vol. 17, no. 2, http://dx.doi.org/10.1061/(ASCE)GM.19435622.0000702

Mao, L, Liu, H, Zhu, Y, Zhu, Z, Guo, R \& Chiang, F 2019, '3D strain mapping of opaque materials using an improved digital volumetric speckle photography technique with X-ray microtomography', Applied Sciences, vol. 9, no. 7, https://doi.org/10.3390/ app9071418

Munoz, H \& Kiyota, T 2020, 'Deformation and localisation behaviours of reinforced gravelly backfill using shaking table tests', Journal of Rock Mechanics and Geotechnical Engineering, vol. 12, no. 1, pp. 102-111, https://doi.org/10.1016/j.jrmge.2019.06.008

Munoz, H \& Taheri, A 2017, 'Local damage and progressive localisation in porous sandstone during cyclic loading', Rock Mechanics and Rock Engineering, vol. 50, no. 12, pp. 3253-3259, https://doi.org/10.1007/s00603-017-1298-8

Munoz, H \& Taheri, A 2019, 'Postpeak deformability parameters of localised and non-localised damage zones of rocks under cyclic loading', Geotechnical Testing Journal, vol. 42, no. 6, https://doi.org/10.1520/GTJ20170266

Munoz, H, Taheri, A \& Chanda, EK 2016, 'Pre-peak and post-peak rock strain characteristics during uniaxial compression by 3D digital image correlation', Rock Mechanics and Rock Engineering, vol. 49, no. 7, pp. 2541-2554, https://doi.org/10.1007/s00603016-0935-y

Naganathan, S, Razak, HA \& Hamid, SNA 2012, 'Properties of controlled low-strength material made using industrial waste incineration bottom ash and quarry dust', Materials \& Design, vol. 33, pp. 56-63, https://doi.org/10.1016/ j.matdes.2011.07.014

Nguyen, TL, Hall, SA, Vacher, P \& Viggiani, G 2011, 'Fracture mechanisms in soft rock: identification and quantification of evolving displacement discontinuities by extended digital image correlation', Tectonophysics, vol. 503, no. 1-2, pp. 117-128, https://doi.org/10.1016/j.tecto.2010.09.024

Oka, F, Shahbodagh, B \& Kimoto, S 2018, 'A computational model for dynamic strain localisation in unsaturated elasto-viscoplastic soils', International Journal for Numerical and Analytical Methods in Geomechanics, vol. 43, no. 1, pp. 138-165, https://doi.org/10.1002/nag.2857

Orejarena, L \& Fall, M 2010, 'The use of artificial neural networks to predict the effect of sulphate attack on the strength of cemented paste backfill', Bulletin of Engineering Geology and the Environment, vol. 69, no. 4, pp. 659-670, https://doi.org/10.1007/s10064-010-0326-7

Panteleev, I, Plekhov, O, Pankov, I, Evseev, A, Naimark, O \& Asanov, V 2014, 'Experimental investigation of the spatio-temporal localisation of deformation and damage in sylvinite specimens under uniaxial tension', Engineering Fracture Mechanics, vol. 129, pp. 38-44, https://doi.org/10.1016/j.engfracmech.2014.08.004

Qian, G, Huang, T \& Bai, S 2011, 'Use of cement-stabilised granite mill tailings as pavement subbase', Journal of Materials in Civil Engineering, vol. 23, no. 11, pp. 1575-1578, https://doi.org/10.1061/(asce)mt.1943-5533.0000276

Rankine, RM \& Sivakugan, N 2007, 'Geotechnical properties of cemented paste backfill from Cannington Mine, Australia', Geotechnical and Geological Engineering, vol. 25, no. 4, pp. 383-393, https://doi.org/10.1007/s10706-006-9104-5

Shadmehri, F \& Hoa, SV 2019, 'Digital image correlation applications in composite automated manufacturing, inspection, and testing', Applied Sciences, vol. 9, no. 13, https://doi.org/10.3390/app9132719

Sivakugan, N, Veenstra, R \& Naguleswaran, N 2015, 'Underground mine backfilling in Australia using paste fills and hydraulic fills', International Journal of Geosynthetics and Ground Engineering, vol. 1, no. 2, https://doi.org/10.1007/s40891-015-0020-8 
Song, H, Zhang, H, Kang, Y, Huang, G, Fu, D \& Qu, C 2013, 'Damage evolution study of sandstone by cyclic uniaxial test and digital image correlation', Tectonophysics, vol. 608, pp. 1343-1348, https://doi.org/10.1016/j.tecto.2013.06.007

Sun, Q, Cai, C, Zhang, S, Tian, S, Li, B, Xia, Y \& Sun, Q 2019, 'Study of localised deformation in geopolymer cemented coal gangue-fly ash backfill based on the digital speckle correlation method', Construction and Building Materials, vol. 215, pp. 321-331, https://doi.org/10.1016/j.conbuildmat.2019.04.208

Tung, ND \& Tue, NV 2015,' Post-peak behavior of concrete specimens undergoing deformation localisation in uniaxial compression', Construction and Building Materials, vol. 99, pp. 109-117, https://doi.org/10.1016/j.conbuildmat.2015.09.013

van Mier, JGM 2008, 'Framework for a generalised four-stage fracture model of cement-based materials', Engineering Fracture Mechanics, vol. 75, no. 18, pp. 5072-5086, https://doi.org/10.1016/j.engfracmech.2008.07.011

Weidner, A \& Biermann, H 2021, 'Review on strain localisation phenomena studied by high-resolution digital image correlation', Advanced Engineering Materials, vol. 23, no. 4, https://doi.org/10.1002/adem.202170011

Zhang, H, Huang, G, Song, H \& Kang, Y 2012, 'Experimental investigation of deformation and failure mechanisms in rock under indentation by digital image correlation', Engineering Fracture Mechanics, vol. 96, pp. 667-675, https://doi.org/10.1016/j.engfracmech.2012.09.012

Zhang, J, Deng, H, Taheri, A, Deng, J \& Ke, B 2018, 'Effects of superplasticiser on the hydration, consistency, and strength development of cemented paste backfill', Minerals, vol. 8, no. 9, https://doi.org/10.3390/min8090381

Zhang, J, Soltani, A, Deng, A \& Jaksa, MB 2019, 'Mechanical performance of jute fiber-reinforced micaceous clay composites treated with ground-granulated blast-furnace slag', Materials, vol. 12, no. 4, https://doi.org/10.3390/ma12040576

Zhao, Y, Soltani, A, Taheri, A, Karakus, M \& Deng, A 2018, 'Application of slag-cement and fly ash for strength development in cemented paste backfills', Minerals, vol. 9, no. 1, https://doi.org/10.3390/min9010022

Zhao, Y, Taheri, A, Karakus, M, Chen, Z \& Deng, A 2020, 'Effects of water content, water type and temperature on the rheological behaviour of slag-cement and fly ash-cement paste backfill', International Journal of Mining Science and Technology, vol. 30, no. 3, pp. 271-278, https://doi.org/10.1016/j.ijmst.2020.03.003

Zhao, Y, Taheri, A, Soltani, A, Karakus, M \& Deng, A 2019, 'Strength development and strain localisation behavior of cemented paste backfills using Portland cement and fly ash', Materials, vol. 12, no. 20, https://doi.org/10.3390/ma12203282 